\title{
Arte, tecnología y género. (Nuevos) escenarios artísticos contemporáneos para la lucha
}

\author{
Marcelino García Sedano \\ Universidad San Francisco Quito
}

\section{RESUMEN}

La actual resistencia política al poder desde el arte tecnológico y algunos de sus ejemplos, parten de una relectura de las teorias de biopoder y tecnopoder que deriva en nuevas formas de repensar el género. Esta reflexión se materializa en un activismo artístico que evoluciona históricamente desde ejemplos anteriores como el ciberfeminismo. Surgen nuevos escenarios de lucha, una nueva bioética y sin duda, un nuevo escenario político. Estas nuevas realidades representan la gran capacidad que este tipo de arte demuestra para revisar y desmontar acciones de poder preestablecidas como las que tienen lugar dentro del neoliberalismo, el esquema colonial de raza y sexo, la contemplación binaria del género y la aplicación de políticas de control basadas en prefectos morales. Este panorama contemporáneo de disidencia artística se evidencia mediante el análisis de las obras, artistas y teóricos expuestos en esta disertación.

Art, technology and gender. (New) contemporary scenarios for gender equality.

PALABRAS CLAVE

Ciberfeminismo; tecnopoder; arte y tecnología; activismo.

ABSTRACT

Today's resistance of technological art towards power takes as a starting point theories such as biopower and techno-power, which implies new ways of thinking gender. This perspective becomes a form of artistic activism rooted in pass examples of cyberfeminism. New struggles and new bioethics that lead to brand-new politics appears. These new realities evidence the extraordinary capacity of these new forms of art to question and dismantle the powers that shape neoliberalism and the colonial order in sex, race, gender binarism, and in politics of control based on moral conceptions. The contemporary landscape of dissenting art practices is evident in the study of artistic works, artists and thinkers tackled in this dissertation.

Cyberfeminism; technopower; art and technology; activism. 


\section{Introducción}

Las teorías de género y las acciones de resistencia al poder orquestadas desde este paraguas teórico-político, han evolucionado paralelamente al desarrollo de las nuevas tecnologías, especialmente las digitales. Los ejemplos de resistencia política dirigidos desde la militancia a favor de la igualdad de género y la necesidad de repensar todas las características y posibilidades del mismo, han utilizado estas tecnologías como terreno fértil y eficaz para sus objetivos. Tomando como ejemplo el ya conocido movimiento del ciberfeminismo, en la actualidad, el movimiento feminista tecnológico, manifiesta diferencias sustanciales. Asistimos al desarrollo de ejemplos que desde otros ámbitos más allá de la red utilizan tecnologías de reciente creación, algunas claramente diseñadas para el control, replantean un nuevo campo de batalla expandido. Un terreno de discusión donde se producen discursos que extienden las teorías antes mencionadas a los actuales y complejos escenarios de aplicación de sofisticadas y en ocasiones invisibles, estrategias de biopoder.

Muchas de las manifestaciones artísticas recogidas en este artículo provienen de la intersección entre activismo político y arte, utilizando la tecnología como soporte y pensando de forma crítica acerca de ella. Es en esta indefinición entre lo político y lo artístico donde estos discursos adquieren la eficacia necesaria para considerar cuáles son las fronteras y límites de lo artístico. Debido a la enorme capacidad de interacción y modificación de las conductas sociales y de la aplicación de estrategias de control y poder que tiene el desarrollo de la tecnología para estos fines, es necesario entender que, al plantear proyectos artísticos dentro de la reflexión que nos ocupa, se constituyen herramientas precisas de diálogo y cuestionamiento de un orden prestablecido basado en el esquema colonial sexo/raza y en el entorno ideológico del neoliberalismo que lo respalda.

El objetivo de este artículo es recoger algunos de estos ejemplos y dar constancia de la evolución que han tenido este tipo de resistencia artística y política en los últimos tiempos, demostrando así la eficacia que este escenario compuesto por la triada arte, tecnología y feminismo tiene para repensar el género desde las posibilidades, características y contradicciones de la esfera tecnológica.

\section{Género, biopoder, tecnología y arte}

En el panorama tecnológico actual que preside la mayor parte de la interacción social del ser humano y la condiciona, el concepto foucaltiano de anatomopolítica o control de las personas de forma individual por parte de los estados, retoma especial protagonismo, permitiendo definir y visibilizar muchas de las acciones de control sobre los cuerpos que provienen de las tecnologías de biopoder. Estas acciones tienen un origen descentralizado, flexible e invisible y se ocupan no sólo el dominio sobre lo físico sino también sobre la vida y los aspectos sociales de los ciudadanos. Cuando Foucault definió y enumeró las tecnologías que controlaban los cuerpos para asegurarles una utilidad y una integración dentro del sistema político y económico, sentó las bases para entender la evolución de esos procesos cada vez más sofisticados y la posibilidad de extenderlos a la actualidad. Las tecnologías han cambiado, pero continúan existiendo procesos y políticas que intervienen de distinta forma en numerosos aspectos. Dentro de estas dinámicas, nos interesan sobre todo las que relacionan el cuerpo con el género, así como las que se aplican sobre el concepto de sexo, resultado de diversas estrategias de poder que devienen en la intencionalidad y urgencia de definir nuestra subjetividad. ${ }^{1}$ El desarrollo de tecnologías, no sólo digitales sino también en el campo de la biotecnología, la genética y todas aquellas disciplinas que potencialmente pueden mejorar y modificar la condición biológica humana, pueden ser analizadas en relación con las teorías postfeministas y "queer". Estas perspectivas permiten determinar qué relación tienen este conjunto de técnicas con el binario sexo-género, en qué medida contribuyen a su separación o, por el contrario, qué posibilidades tienen para desmontar este posicionamiento histórico. ${ }^{2}$

Las teorías "queer" como herramientas metodológicas, permiten pensar de forma analíti-

FOUCAULT, Michel, Historia de la sexualidad I: la voluntad de saber. Traducción de Ulises Guinazú, Siglo XXI Editores, México, 1998, pág 205.

2 FERNANDEZ, Isabel, "Anatomopolítica y cuerpos sexuados: aproximación a la hermenéutica feministade la segunda mitad del siglo XX". XII Congreso Español de Sociología Grandes transformaciones sociales, nuevos desafíos para la sociología. pág 2, Gijón, Asturias Recuperado de: http://www.fes-sociologia.com/files/ congress/12/papers/3913.pdf 
ca aquellas subjetividades que quedan fuera de la normatividad político, cultural y social así como su poder para modificar y combatir sus pautas, criterios y trascendencia política. Teorías que se encargan de visibilizar los cuerpos que dentro de una sociedad patriarcal no importan y no existen, aquellos sumidos en las dinámicas de control sobre las corporeidades no hegemónicas, ajenas al concepto de ciudadano, seres a la deriva. Judith Butler quien a partir de la teoría performativa del género plantea que tanto el sexo como el género son constructos socioculturales, demuestra que ambos aspectos del individuo están sujetos al poder y sus restricciones, un poder ejercido desde el dominio hegemónico heterosexual. Ese poder no hace más que ensalzar y promover como resistencia natural lo "queer" a manera de postura política. Butler, al negar una metafísica del género confirma que la anatomopolítica, no hace más que ensalzar la sexualización binaria de los cuerpos y transportando el título de su célebre trabajo, delimitar cuáles son los cuerpos que importan. $^{3}$ El panorama tecnológico contemporáneo dedicado al control no hace más que subrayar esa división, jerarquización y dominación desde el esquema patriarcal. Al mismo tiempo, no deja duda de que, a pesar del desesperanzador panorama, la misma complejidad del sistema ejecutor de estas estrategias anatomopolíticas, abre posibilidades no sólo al pensamiento, sino también a la acción.

Frecuentemente se han incorporado a estos discursos las teorias de Giorgio Agamben, quien define la soberanía como aquella capacidad de decisión sobre qué cuerpos importan y cuáles merecen vivir. Para entender esto, se debe tener en cuenta los conceptos de "nuda vida" y "homo sacer" que ayudan a replantear el concepto de orden social. Si entendemos la "nuda vida" como aquella existencia vulnerable, expuesta a la muerte y la violencia, encontramos el propósito final de las tecnologías de biopoder y control sobre esas corporeidades frágiles y expuestas a sus manipulaciones. A este término debemos unir el de "homo sacer", concepto rescatado del derecho romano y que designa al individuo expuesto al poder soberano y que se utiliza para ejemplificar a los parias y especificar ese estado del hombre sujeto al

BUTLER, Judith, Cuerpos que importan. Sobre los limites materiales y discursivos del "sexo", Paidós, Buenos Aires, pág. 13. poder y que deambula en la indefinición entre animal y bestia, naturaleza y cultura. A partir de esta traslación del pensamiento de Agamben hallamos el estado indefinido que nos define como seres sociales: ciudadanos sujetos al orden político y social, frágiles escenarios, víctimas y protagonistas del poder sobre los semejantes, el terreno de exclusión sobre el que se cimientan las sociedades modernas. ${ }^{4}$

Se impone, como urgencia, la necesidad de pensar los cuerpos, el género y las libertades al respecto desde la periferia de la norma, desde las propuestas alternativas y la edificación de nuevos baluartes de reflexión, de nuevas subjetividades críticas y de nuevas definiciones del término ciudadano que parte de la definición de seres híbridos. Seres mezcla de máquina, humanos y animales que son los nuevos cuerpos biopolíticos siempre juzgados, constantemente clasificados. $^{5}$

Es aquí donde toma importancia la cultura y por supuesto dentro de ella, el arte como espacio de discusión. Se convierte en un espacio de resistencia con legitimidad histórica y es aquella cultura que emana y utiliza a su favor las tecnologías con el fin preciso de la comunicación, la que permite pensar acerca de las identidades sociales y por supuesto la construcción y reflexión acerca de las subjetividades sometidas y moldeadas por las tecnologías de biopoder. ${ }^{6}$ Estas subjetividades emergen formando parte de discursos artísticos que, basados en la libertad metodológica que permiten las acciones creativas, ponen en discusión aquellos elementos claves de las teorías de género que buscan no sólo la reflexión, sino que reclaman también la acción. Manifestaciones artísticas que puedan establecer nuevas visiones y horizontes para aquellas subjetividades que quedan fuera de la norma, incluidas como ejemplos de ésta, las instituciones más tradicionales del arte. Es por ello que numerosas veces recurren los artistas a las actitudes más cercanas al activismo político, al hacktivismo e incluso, extienden la herencia estética de lo "ciberpunk", univer-

\footnotetext{
AGAMBEN, Giorgio, Homo Sacer. El poder soberano y la nuda vida I, Pre-Textos, Valencia, 1995, 141

5 BALZA, Isabel, "Ciudadanía y nuevas identidades de género: sobre biopolítica y teoría queer”, Presente, pasado y futuro de la democracia, 2009, pág. 236.

6 MARTÍNEZ, Ana, "Prácticas artísticas y activistas feministas en el escenario electrónico. Transformaciones de género en el futuro digital", Asparkia, 22, 2011, pág. 101.
} 
so ficticio que sirve como recurso argumental para plantear futuros distópicos consecuencia de un gran avance tecnológico que penaliza la calidad de vida de los humanos en todos los sentidos. Manifestaciones artísticas que toman formas de rebelión e insurgencia desde la especulación creativa recuperando la reflexión sobre y desde el cuerpo. Una corporeidad pensada desde el arte, dotándola de nuevas formas y trasladándola a nuevos escenarios, evolucionando como medio de expresión y especulación presente con anterioridad en las pioneras manifestaciones artísticas performáticas de autoras como VALIE EXPORT, Eleonor Antin, Judy Chicago o Annie Sprinkle por mencionar algunos ejemplos. La concepción del cuerpo, sujeto a los designios y capacidades de los adelantos médicos y biológicos como resistencia al biopoder anatomopolítico, toma nuevas dimensiones a partir de la toma de consciencia de éste como producto del poder y como un artefacto productivo que puede ser modificado en pos de una función o el aumento de sus capacidades. ${ }^{7}$

\section{Arte y género en las sociedades tecnológicas}

Hace más de dos décadas una de las tendencias más críticas del pensamiento feminista fue el ciberfeminismo. Un movimiento artístico y político que se apropió de la red desde el deseo utópico de habitar un territorio libre, susceptible de ser poblado por seres soberanos y diferentes en esencia a los que habitaban el terreno físico, el mundo real. No obstante, la vigencia de la evolución del biopoder foucaltiano al de tecnobiopoder acuñado por Donna Haraway en los años 90, debe ser recordada y añadida al conjunto de posicionamientos teóricos mencionados con anterioridad. Es la contingencia del "poder ser" la que expande y abraza toda idea de evolución humana mucho más allá del plano de las capacidades físicas. Este aspecto permite constituir nuevos seres con una gran dimensión política y una capacidad evolutiva que se basa en lo científico, en el laboratorio y resulta en el "tecnocuerpo", entidad expuesta a las acciones de la sociedad de control y en constante evolución. El cuerpo tecnificado, actor protagonista

ESCOBAR, Jorge M, "El cuerpo como artefacto: tecnologías médicas, anatomopolítica y resistencia”, Ciencias Sociales y Educación, Vol. 4, № 7, 2015, pág. 420. sin duda de la cibercultura, pero también elemento bisagra entre las máquinas y el ser humano de carne y hueso, es un ser que escapa al dualismo cartesiano donde el sentido de dividir cuerpo y mente pierde su validez. Un cuerpo que se renueva constantemente, un "cyborg" indeterminado sexual y racialmente, aunque sujeto a la influencia del poder al que resiste. ${ }^{8}$ Este nuevo protagonista mezcla de la evolución conjunta entre tecnología y sociedad mantiene aun la contingencia necesaria en su capacidad de agencia. Como reclama Judy Wajcman, la emancipación política de la tecnología debe pasar primero por el ser humano, requiere lo que denominó "wetware", un espacio intersticial entre la sociedad que debe contemplar la tecnología como parte de su tejido social. ${ }^{9}$ Nuevamente se produce la disolución de los sistemas dialécticos que han presidido incluso, gran parte de los discursos feministas tradicionales. Es en este agente político, llamado "cyborg" si se quiere, que se encarna el mundo de futuros posibles, de seres imaginarios prestos a formar nuevas entidades subjetivas fruto de la mezcla entre máquina, cuerpo y metáfora y horizonte de nuevas políticas corporales. ${ }^{10}$ Por lo tanto, la figura que perfiló Haraway mantiene su total operatividad como eje de un pensamiento que plantea las discusiones basado en la vigencia de la distinción entre animal y humano, físico y no físico, natural y artificial. ${ }^{11}$

Partiendo de esto surgieron las bases metodológicas del ciberfeminismo, elaboradas en su mayor parte por pensadoras tecnoutópicas que percibieron la posibilidad de disolver las fronteras entre género y sexo a partir de la tecnología digital, recreando un contexto ideológico propio de la ciencia ficción. Las primeras ciberfeministas replanteaban un universo de especulación considerado mayormente misógino que provenía del universo del ciberpunk, del que, no obstante, rescatan las posibilida-

${ }^{8}$ GÓMEZ, Sebastián, “TECNO-BÍOS: Una aproximación biopolítica a la relación cuerpo-máquina en el contexto cibercultural contemporáneo", Aisthesis no 52, 2012, pág. 345.

9 WAJCMAN, Judy, El tecnofeminismo, Cátedra, Madrid, 2006, pp. 120-161

10 HARAWAY, Donna, Ciencia, cyborgs y mujeres. La reinvención de la naturaleza, Ediciones Cátedra. Instituto de la Mujer, Valencia, 1991, 364.

11 BOYER, Amalia, "Biopolítica y filosofía feminista", Revista de Estudios Sociales, núm. 43, mayo-agosto, 2012, pág. 135. 
des de liberación implícitas en internet. ${ }^{12} \mathrm{La}$ posibilidad de dejar atrás un cuerpo históricamente limitado por los estereotipos binarios a partir de la proyección de nuevas corporeidades digitales o poscuerpos, sustentaba ideológicamente las posibilidades de cambio hacía un posgénero.

Linda Dement propuso en 1995 "Cyberflesh Girlmonster" (fig. 1), una acción que partía del escaneo de ciertas partes corporales de unas treinta mujeres, un conglomerado de fragmentos de cuerpos y sus sonidos, que reorganizados y dotados de interactividad conformaron una suerte de cuerpos monstruosos, una respuesta irónica al concepto de la representación de la feminidad hegemónica desde las nociones de deseo, venganza y violencia. ${ }^{13}$ Los trabajos multimedia de Dement, colgados en la red, proponían de forma temprana un espacio libre de patriarcado y una respuesta a la convencional búsqueda de cuerpos femeninos para el ocio y el placer.

Así mismo, el colectivo VNS Matrix, es decir Virginia Barrat, Francesca da Rimini, Julianne Pierce y Josephine Starrs, plantearon dentro de sus numerosos proyectos nuevas corporeidades a partir de las facilidades que la red y las nuevas tecnologías permitían, partiendo de la capacidad utópica de proyectar esencialidades, ontologías e identidades ex nuovo. En "All New Gen" (1992), una respuesta al machismo presente en los videojuegos desde un hipotético videojuego que tomaba la forma artística de una instalación multimedia, se combatía al patriarcado ejemplificado en la industria militar, el régimen de los superhéroes, la propaganda y demás valores negativos del contexto de un supervillano conocido y creado como "Big Daddy". El usuario, al que se recomienda elegir el género "sin especificar", se convierte en un

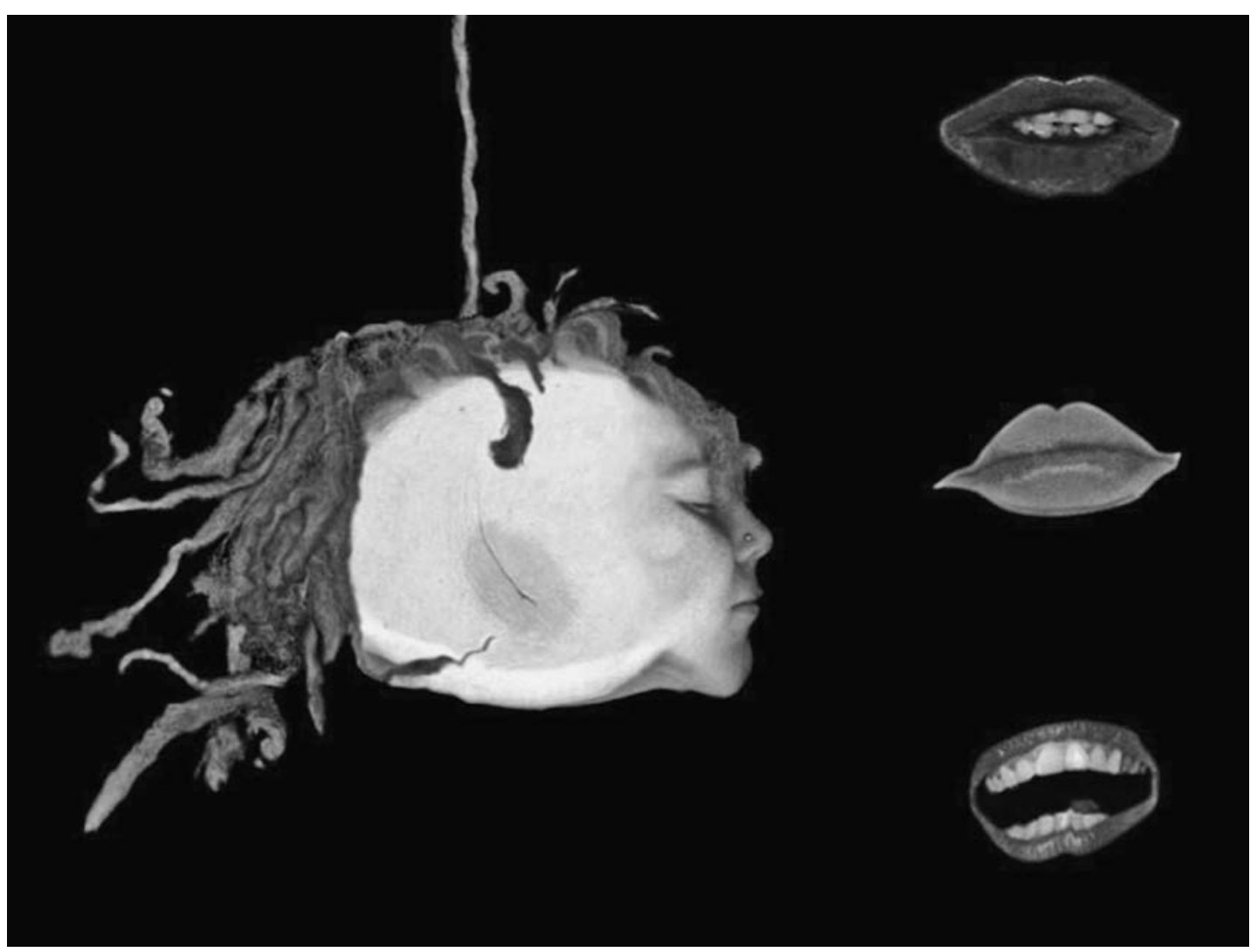

Fig. 1. Linda Dement, Cyberflesh Girlmonster, 1995. http://lindadement.com/images/cfgm/CFGM20.jpg

EVANS, Claire L., "Ciberfeminism”, 2014, Deep Lab. http://deeplab.net

13 DEMENT, Linda, Linda Dement, 2018, Recuperado de http://www.lindadement.com/cyberflesh-girlmonster. htm 
ciberanarquista, un "DNA Slut" o "puta de AD$\mathrm{N}$. ${ }^{14}$ Una recreación de un universo virtual en el que cada elemento o personaje eran una crítica feroz al orden preestablecido y que permitía vivir al usuario, a través de su propia experiencia, los detalles de esta situación de desigualdad a la par que combatirla de forma simbólica.

Sadie Plant, otra figura clave del primer ciberfeminismo, realizó un aporte significativo a la relación del feminismo con las tecnologías digitales más allá de las posibilidades de un nuevo cuerpo libre de esquemas. Plant veía en las posibilidades de conexión de la red de una forma no centralizada la esencia de una feminidad plural más acorde a su propia naturaleza y que podría desembocar en un poder horizontal, un poder que se extienda de todos a todos ${ }^{15}$. Fue de las primeras en ver las posibilidades de asociación con fines políticos de la red y aplicarlas a la lucha de género.

La hipótesis de que la red es un entorno libre, continúa transformándose con la consolidación del panorama neoliberal, condicionando y cambiando las manifestaciones de resistencia que provienen de este entorno y vinculando sus esfuerzos a cuestionar las libertades y sus coacciones desde un entorno digital corporativista. Es dentro de esta relación compleja y tensa con el neoliberalismo que se desarrollan muchas de las teorías feministas digitales y de género, resultando por esta confrontación ideológica numerosas contradicciones y preguntas de difícil respuesta. Hester Baer señala una ambigua relación entre el pensamiento neoliberal y el desarrollo de las subjetividades. Relación que plantea una revisión activista del género desde el análisis de su efectividad real, teniendo en cuenta la sobreabundancia de manifestaciones culturales en la red y su descentramiento, así como su capacidad de generar solidaridad. ¿Acaso alguna militancia de género en la red no está en línea con algunos aspectos de la promoción de la autogestión, el individualismo y la autopromoción tan relacionada con el discurso liberal? ${ }^{16}$ Sólo basta pensar en la efectividad, pero también en la labor de cohesión social de los hastag reivindicativos y demás microrrebe-

14 VNS Matrix, VNS Matrix, 2018, Recuperado de https:// vnsmatrix.net/projects/all-new-gen

15 PLANT, Sadie, Zeros + ones. Digital women + The new technoculture, Fourth Estate, Londres, 1998, pág. 10.

16 BAER, Hester, "Redoing feminism: digital activism, body politics, and neoliberalism", Feminist Media Studies, 2016 VOL. 16, NO. 1, pág. 18. liones orquestadas desde las redes sociales. Por tanto, estamos ante una evolución de aquellos planteamientos utópicos, rebeldes e irreverentes del ciberfeminismo primigenio que resulta en una sofisticación de las estrategias de lucha cuya eficacia aun no podemos comprobar más allá de la certeza de su propia existencia y, por lo tanto, de su valor cuestionador.

También para algunas autoras como Vicky Kirby, utilizar la figura del "cyborg" es recrearse en un juego dialéctico ya que, para ella, el concepto fue creado desde el entorno posmoderno y humanista. Esta figura parodia y recupera la biología como un discurso, por lo que difícilmente puede justificarse como ese pretendido nuevo ente liberador si incurrimos en estas contradicciones. ${ }^{17}$ De nuevo, una revisión y el plantamiento de una nueva base operativa a partir de la metodología y combatividad ciberfeminista desde una actualización del "viejo" panorama.

No obstante, ahora son varias las plataformas desde las que se trabaja partiendo de este enfoque que ve en el trabajo en red y el ciberespacio una de las metodologías de resistencia más adecuadas, continuando esa tradición iniciada en los años noventa, pero bajo nuevos esquemas. Se busca una feminización de internet que deconstruya y rompa la jerarquía del orden preestablecido, proponiendo y posibilitando la destrucción de la dualidad en busca de una identidad múltiple, reestructurada y subversivamente articulada. El feminismo en red y desde la red, trabaja ahora desde la micropolítica, desafiando el sexismo, la misoginia, la homofobia y los demás discursos de opresión que provienen de determinados esfuerzos y ejemplos de comunicación, la mayor parte de las veces con fines comerciales, presentes en el devenir cibernético. ${ }^{18}$

El colectivo Deep Lab es un ejemplo continuador y transformador de la tradición ciberfeminista veinticinco años después. Aunque rechaza las ciberutopías, no niega la utilidad del entorno digital para la lucha de género. Compuesto por un grupo colaborativo de investigadoras, escritoras, ingenieras, artistas y productoras culturales, desarrollan desde el esquema

\footnotetext{
17 KIRBY, Vicky, Telling Flesh. The Substance of the Corporeal. Routledge, Nueva York y Londres, 1997, pág. 147.

18 MUNRO, Ealasaid, “Feminism: A Fourth Wave?", Political Insight 4, 2013, pág. 23.
} 
expandido de laboratorio y de colectividad un foro de discusión e investigación sobre conceptos como la vigilancia, la privacidad, el capitalismo, el hacktivismo social o el arte entre otros muchos temas. Su metodología tiende lazos entre el conocimiento científico y la creatividad como medio de expresión y análisis que se concretan a través de conferencias, proyectos artísticos y elaboración de herramientas informáticas que enfrentan los problemas habituales del género inmerso en lo digital, el femenino y todos los posibles géneros más allá del binario, que han sido desplazados del mundo de la tecnología digital y que así pueden reclamar su espacio. ${ }^{19}$

\section{Nuevas aproximaciones a la lucha de género desde la tecnología y el arte}

Valorando los planteamientos ciberfeministas como punto de partida para la elaboración de nuevos discursos subjetivos, asistimos en la actualidad a nuevas aproximaciones desde la tecnología y el arte que intentan resignificar este contexto hipertecnologizado donde las necesidades, identidades y demás características esenciales de la persona se configuran en conjunto con esas tecnologías. ${ }^{20}$ Surgen nuevos escenarios de reflexión en torno a la genopolítica y la vida artificial, así como nuevas formas de navegación e interacción colectiva en red, que exigen, ante la novedad de sus formas, nuevas urgencias, nuevos intentos de análisis y resolución.

La genopolítica es aquella forma de poder que atiende a las posibilidades de transformación de la estructura biológica del ser humano y que propiciada por los avances en tecnologías médicas supone una evolución del concepto de biotecnopoder entroncado directamente con las teorías transhumanistas. Es aquí, interesante la reflexión de Santiago Díaz quien indica que si la anatomopolítica regulaba los cuerpos y la biopolítica la población, la genopolítica, no sólo pretende regular, sino crear a la humanidad. ${ }^{21}$ Este giro interesante permite ver en ello una nueva forma de neocolonialismo más allá de la continuidad del esquema sexo/raza con el

19 DEEP LAB, Deep Lab, 2018, Recuperado de http://www. deeplab.net/aboutus

20 WAJCMAN, Judy, El tecnofeminismo, opus cit., pág. 151.

21 DÍAZ, Santiago, "El biopoder de la biotecnología o el biotecnopoder. Aportes para una bio(s)ética”. Ludus Vitalis, vol. XIX, num. 36, 2011, pp. 196-197. alejamiento de estas posibilidades a los países más pobres, regulando y limitando sin duda las posibilidades a los cuerpos más privilegiados, categorizando estos a partir de la distribución de los recursos y los saberes en materia de genotecnología.

A partir de la aplicación de estas biotecnologías, artistas como Giulia Tomasello plantean discursos que rebaten estas mutaciones del término biopoder, evidenciando las connotaciones éticas que flotan en torno a estas posibilidades. "Future flora" (2019) es un proyecto que surge del master Material Futures del Central Saint Martins para replantear la trascendencia y alcance de la infección por candidiasis en mujeres (fig. 2).

El proyecto permite cultivar en casa las bacterias que combaten la cándida mediante un incubador dotado de tecnología arduino que se aplica posteriormente mediante un gel usado como si fuese una toalla sanitaria. De esta forma, las mujeres no solo forman parte del conocimiento científico, sino que toman control de sus cuerpos más allá de las políticas económicas de las farmacéuticas. La higiene íntima, sale también de la oscuridad a la que la moral imperante le condena, replanteando un debate ético sobre la misma y empoderando sin duda a las usuarias mediante un control más directo sobre sus cuerpos y por consiguiente sobre su sexualidad. La autora reclama también, un regreso a lo biológico y a la subjetividad del individuo que debe posicionarse para emerger del mundo digital, ámbito que en cierta forma ejerce su poder uniformizador y alienante arrastrándonos a un mundo inmaterial. ${ }^{22}$

Las ideologías conservadoras de corte heteropatriarcal influenciadas casi siempre por morales religiosas han intervenido siempre en la capacidad de decisión de la mujer sobre su maternidad. Una de las mayores formas de ejercer un control sobre esto es sin duda la regulación legislativa sobre el aborto, un derecho ausente en muchos lugares. "Abortion drone" (2015) es un proyecto que se sirve de los drones, la popular tecnología empleada con fines bélicos , para bombardear con píldoras abortivas países donde estas medicinas no son legales. Con este tipo de acciones, la primera fue transportar píldoras desde Alemania a Polonia

\footnotetext{
TOMASELLO, Giulia, Future Flora. Giulana Tomasello, 2018, Recuperado de https://gitomasello.com/Future-Flora
} 


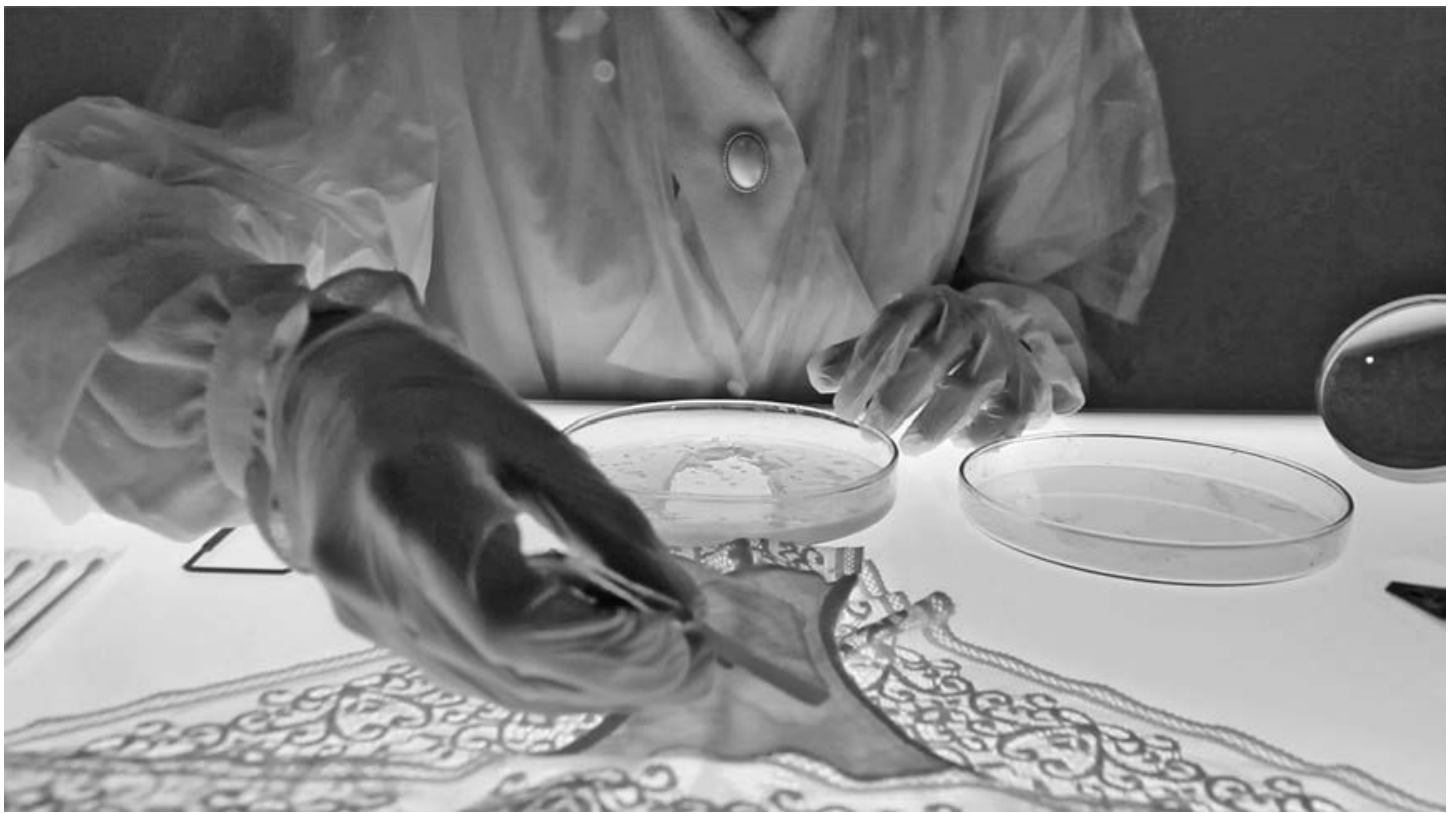

Fig. 2. Giulia Tomasello, Future Flora, 2019. Future flora, https://gitomasello.com/Future-Flora

en 2015, no sólo se evidencia la precariedad y lo absurdo de las restricciones morales, sino también las legislaciones sobre este aspecto así como el control de tránsito entre países. Esta primera intervención desató acciones legales de los dos países y expuso lo fácil que es abortar con medicinas que son consideradas legales, así como la clandestinidad y el riesgo que se toman algunas mujeres para interrumpir el embarazo en países donde no es permitido. ${ }^{23}$ El proyecto, anónimo por razones obvias, es también una fuente de información sobre cómo realizar el procedimiento y se parece bastante al que se ofrece desde la plataforma $\mathrm{CH} 2$ Open Source Abortion. Este experimento replantea de forma crítica el panorama socio-político estadounidense distribuyendo el texto "A Womb of One's Own: Taking Charge of Your Reproduction Without Doctors" (2014) escrito por Jane Doe que propone una política de intervención ajeno a la industria médica reivindicano la libertad social y el sentido de comunidad..$^{24}$ Estas estrategias analizan qué es ser mujer en relación con la tecnología y cómo la relación entre género y tecnociencia es cada vez más complicada y he-

23 HERTZ, Garnet, Disobedient Electronics. Protest, 2018, pág. 3. Recuperado de http://www.disobedientelectronics.com/

24 DOE, Jane, A Womb of One's Own: Taking Charge of Your Reproduction Without Doctors, 2014, pp. 5-9, Recuperado de https://wombofonesown.wordpress.com/ redera de un proceso evolutivo largo y múltiple que se debe y se puede empezar a cambiar. ${ }^{25}$

"A piece of Pie Chart" (2017) de Annina Rüst, replantea a través de un robot que fabrica tartas la desigualdad de género en el ámbito de la tecnología y el arte (fig. 3). No es para nada casual que el elemento para demostrar la desigualdad haya sido una tarta. Este tipo de acciones domésticas como son la cocina y la costura por mencionar algunas, están asociadas de forma tradicional a las mujeres. Un tipo de producción que, si bien tiene como fin el ámbito familiar en muchas ocasiones, no escapa a estar inscrito dentro del sistema capitalista. Este tipo de acciones llevadas a cabo por mujeres anónimas, convierte a las mismas, según Remedios Zafra, en "prosumers", productores que necesitan consumir previamente para generar este tipo de productos de consumo interno. Esto agota la incidencia y sobre todo evidencia la invisibilización de las mujeres dentro de este sistema de producción, en este caso en el ámbito artístico. ${ }^{26} \mathrm{La}$ decoración de las tartas se hace mediante la representación de gráficas de datos que denuncian esta desigualdad mientras

25 PAUL, Christian, A Companion to Digital Art, First Edition, John Wiley \& Sons, Inc., Chichester, 2016, pág. 181.

26 ZAFRA, Remedios, "Prosumo", (H)adas. Mujeres que crean, programan, prosumen y teclean, Páginas de espuma, Madrid, 2013, pp. 149-150. 


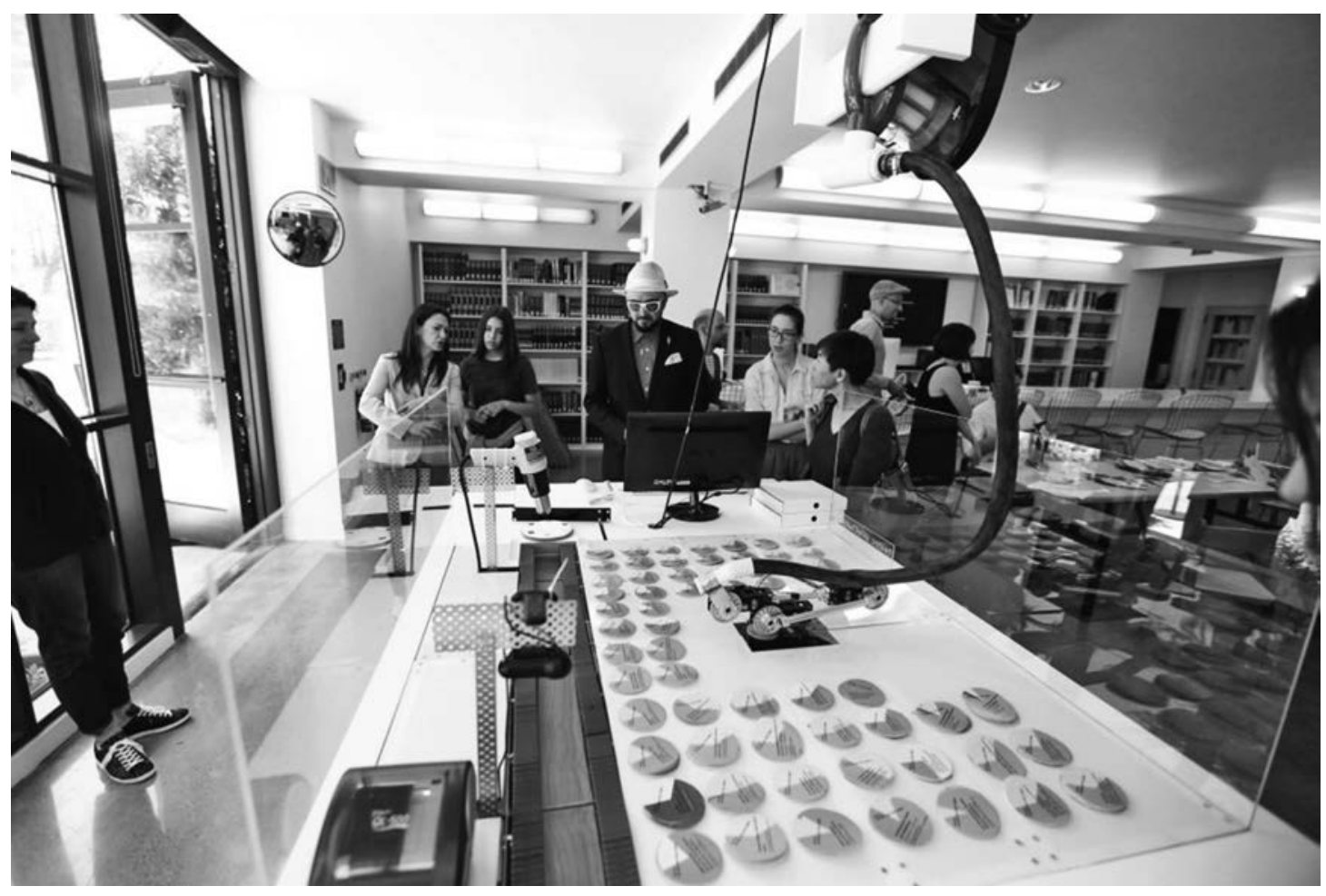

Fig. 3. Annina Rüst, A piece of Chart, 2017. http://www.anninaruest.com/pie/wp-content/uploads/2015/05/IMG_6949-1024x682.jpg

se rememora una especie de línea de producción industrial doméstica. El hecho de utilizar un brazo robótico sustituye toda una serie de maquinarias destinadas a producir en la sombra los electrodomésticos, por un paradigma de la industrialización tecnológica protagonizada y desarrollada en mayor parte por hombres. La obra subvierte este orden heteropatriarcal de forma poética e irónica. ${ }^{27}$ El público interactúa consultando datos concretos sobre la representación de las mujeres en el arte o la tecnología. Muchas veces cuando se consultan las biografías de los artistas no se obtienen datos concretos sobre matices de sexualidad, raza y género y generalmente esta información se provee dentro del esquema tradicional dicotómico masculino o femenino. La tarta resultante es un objeto dialógico de reflexión y discusión que los visitantes al finalizar el evento, pueden elegir enviar a una galería o empresa cómplice de esas estadísticas nefastas o llevársela para poder iniciar una discusión al respecto en otro ambiente. ${ }^{28}$

Ibid. pp 153 - 154.

28 HERTZ, Garnet, Disobedient Electronics. Protest, opus cit., pág. 11.
Stephanie Dinkins, plantea mediante una conversación con "Bina48”(2010), su robot homónimo, la idiosincrasia de ser mujer y ser negra, aunque éste no sea capaz de descifrar qué significan esas dos cosas. Todas las creaciones, incluidas las tecnologías más avanzadas y aquellos seres que conforman la vida artificial, son un reflejo de nuestras debilidades, sean en forma de políticas raciales y sociales, crisis ecológicas, manifestaciones de poder e incluso la búsqueda utópica de la perfección. Esta obra en concreto trae a la luz las críticas al feminismo hegemónico que ignora las convergencias entre raza/clase/sexualidad/género surgidas desde la colonialidad del poder y que fueron discutidas por la teorías decoloniales remarcando el concepto de interseccionalidad que plantea la posibilidad de desmantelar la exclusión histórica de las mujeres no blancas, el denominado por María Lugones, "sistema moderno colonial de género" 29 . Un sistema replicado en el actual entorno digital y tecnológico que sirve, en este caso partiendo de la alegoría de lo robótico,

29 LUGONES, María, “Colonialidad y género: Hacia un feminismo descolonial” en Mignolo, Walter, Género $y$ descolonialidad, Del Signo, Buenos Aires, 2014, pág. 15. 
como una sutil réplica a la complejidad de esta naturaleza ontológica. Las teorías de Lugones parten de las ideas de Quijano quien ya hace algún tiempo definió que el poder se sustentaba en las relaciones de dominación entre diversos actores sociales ubicados por cuestiones y condicionantes históricos entre culturas dominantes y dominadas ${ }^{30}$. María Lugones amplía y complejiza estas ideas que juzga válidas pero limitadas, ya que Quijano argumenta la colonialidad del género partiendo de las relaciones de control sobre el sexo y sus productos desde una perspectiva heterosexual y patriarcal. Según la autora, Quijano asume de esta forma el significado hegemónico de género. Más allá de la relación entre capital y trabajo típica del sistema de género colonial materializada en la autoridad colectiva, motivo histórico de disputa, se deben tener en cuenta nuevos factores: la construcción del conocimiento y las culturas resultantes de este complejo sistema que forman parte de la colonialidad del poder y sus procesos. "Bina 48", en su propio desarrollo no es consciente de estas suttilezas y en su autoaprendizaje evidenciará todas estos aspectos dejándo una pregunta en el aire. ¿se puede construir la identidad de forma artificial?

De igual forma, debemos añadir a las narrativas digitales feministas que cuestionan, entre otras cosas, la identidad en la red y los aspectos epistemológicos de habitar los espacios creados por las nuevas tecnologías de comunicación. Las narrativas feministas que derivan de la red, son espacios definidos por miles de ramificaciones y conexiones que surgen de las interacciones subversivas y de la importancia del hipervínculo. Carolyn Guertin resalta que este puede ser entendido desde la capacidad de volver a ser visitado y revisado implicando la reelaboración del texto, de la acción, volviendo sobre el tiempo, el espacio, modificando, alterando y amplificando el lugar de la crítica, la lucha y la suversión. ${ }^{32}$

Partiendo de las particularidades de este fenómeno debemos tener en cuenta que la

30 QUIJANO, Anibal, "Dominacion cultural", Cuestiones $y$ horizontes : de la dependencia histórico-estructural a la colonialidad/descolonialidad del poder, CLACSO, Buenos aires 2014, pp. 667-689.

31 LUGONES, María, "Colonialidad y género", TABULA RASA No.9, julio-diciembre de 2008, pag 78.

32 GUERTIN, Carolyn, "Wanderlust: The Kinesthetic Browser in Cyberfeminist Space", Extensions Journal, Vol 3, enero 2007, pág. 3. navegación y la programación poseen características afines a la performance. Para entender mejor esto debemos explicar que mientras este entramado de hipervínculos, de códigos y aplicaciones responden a un esquema donde los límites entre lo normal y lo anormal referidos al cuerpo político, están definidos y normatizados, la performance, es decir el navegar e interactuar en estos espacios, replantea esas normas. Habitar la red cuestiona los esquemas heteropatriarcales creando nuevas formas de significado, nuevas identidades y nuevas herramientas para trabajar en favor de la igualdad de género. Igualdad que resulta de la lucha entre relaciones de poder, la lucha política y la resignificación, no solo de la agencia política del "cyborg", sino también del esquema de dominio y el tono del entorno tecnológico. ${ }^{33}$ Una adaptación evolutiva a los nuevos espacios y normas de interacción social. Un desarrollo natural de las posibilidades que había señalado Sadie Plant a partir del concepto de descentralización.

"Periodshare" (2016) de Lone Koefoed Hansen y Marie Louise Juul Søndergaard es un proyecto crítico con la forma en cómo la tecnología consolida las narrativas que definen la normalidad acerca del cuerpo humano, cómo estas trabajan en términos de biopoder y a partir de la censura de lo considerado incorrecto, la exaltación de los cuerpos deseables y todo aquello que tiene que ver con ellos (fig. 4). Utilizando los esquemas neoliberales de emprendimiento en la red y transformándolos en una poderosa herramienta feminista, cuestiona el modelo de negocio que las aplicaciones suponen hoy en día, donde un mayor número de seguidores o una mayor interacción entre estos deriva en una mayor ganancia. "Periodshare", presentado como un kickstarter une las dos cosas, el poder del hipervínculo y la interacción y la metodología de la performance al utilizar la misma esncia de las aplicaciones que monitorizan el periodo y la fertilidad de las mujeres pero manteniéndolo en la sombra. En este caso se convierte en algo público, evidenciando lo que siempre se ha mantenido oculto o con unas connotaciones moralmete definidas por la idea de maternidad tradicional, la fertilidad del cuerpo femenino. Las usuarias de "Periodsha-

PUJOL, Joan y MONTENEGRO, Marisela, "Technology and Feminism: A Strange Couple*”, Revista de Estudios Sociales No. 51, 2014, 180. 


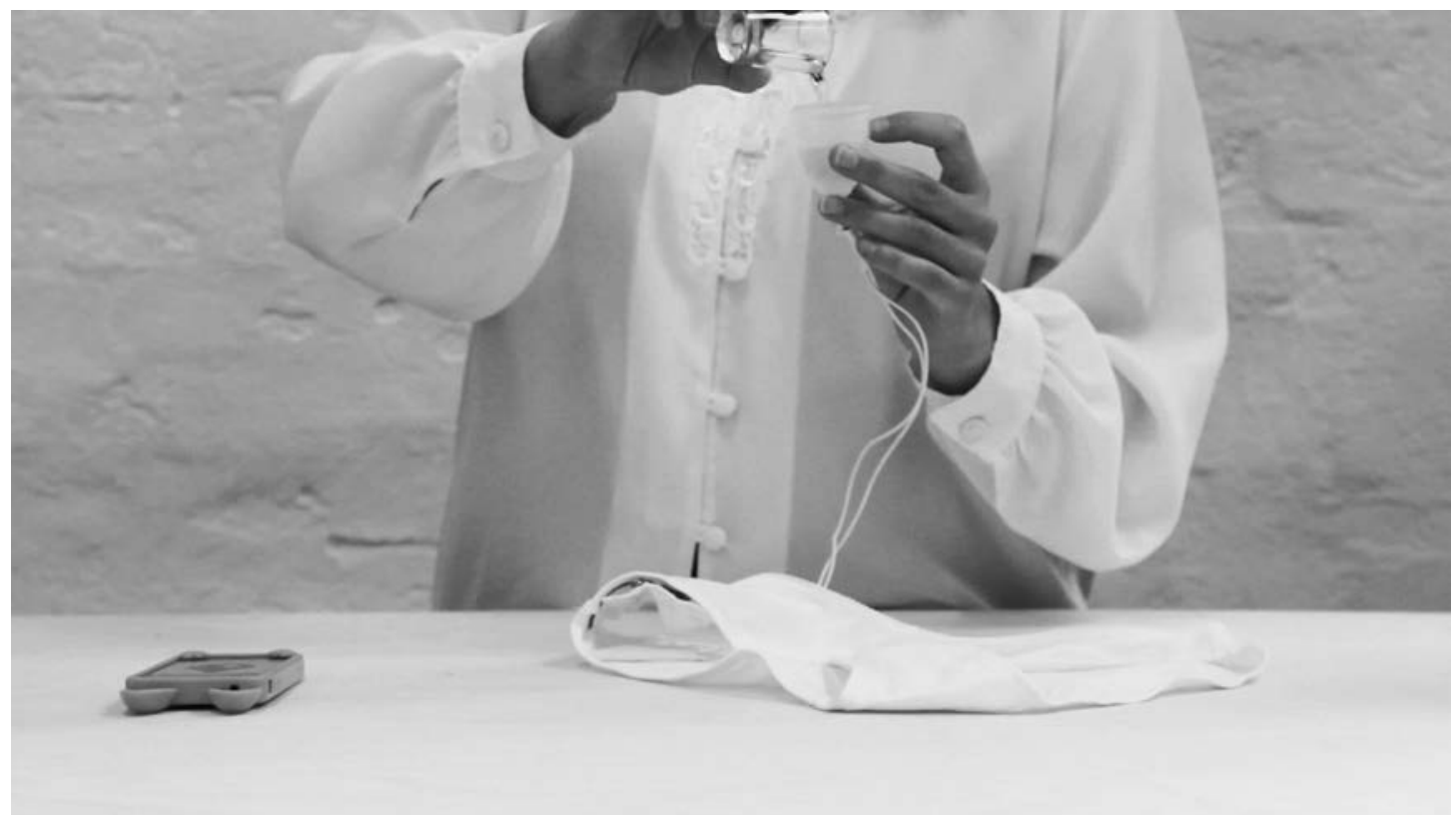

Fig. 4. Lone Koefoed Hansen y Marie Louise Juul Søndergaard, Periodshare, 2016. https://mljuul.com/PeriodShare

re", en un acto performativo, pueden compartir los datos sobre su fertilidad a través de las redes sociales con sus amigos o familiares. Los datos son obtenidos por una copa menstrual con sensores que los transmiten al teléfono móvil. ${ }^{34}$ Este hecho se convierte en una crítica ácida a la necesidad de compartir cualquier acción que los usuarios de redes sociales manifiestan en la actualidad, un exhibicionismo de intimidades intrascendente, vacío y neutro. El asunto de la visibilidad, más allá de esta banalización, responde a intereses de poder. La cantidad de visibilidad de los asuntos sobre identidad de género, es insuficiente, por lo que la interacción con los campos donde su presencia se haria efectiva es pobre e intrascendente: instituciones, discursos, receptáculos de representaciones y discusiones. Es por esa necesidad que la insurgencia feminista de última generación recurre a generar los propios sitios en red como hemos visto en el ejemplo anterior, pero también a elaborar la tecnología propia necesaria bajo un espíritu DIY (hazlo tú misma) que funciona desde la organización comunitaria. El concepto de comunidad promueve no solo la difusión de objetos subversivos tecnológicos, sino también habilidades, formando a un usuario empode-

34 SØNDERGARRD, Marie Luise Periodshare, 2016, Recuperado de https://mljuul.com/PeriodShare rado en el devenir tecnológico. ${ }^{35}$ Marie Louise Søndergaard tiene incluso un proyecto para que las usuarias fabriquen su propio vibrador. Se produce lo que podriamos llamar un descentramiento colaborativo del discurso a través de la creación de colectivos y plataformas que permiten el trabajo desde la red. Algunos ejemplos de colectivos reseñables son .dpi o los españoles Ela Fan Tech o Generatech. Plataformas creadoras de contenido, pero también de comunidad. Como ya subrayó en su momento Remedios Zafra, la importancia del ciberfeminismo actual no reside en la posibilidad de transformación del cuerpo en la búsqueda de un poscuerpo, sino en las posibilidades y el poder de la alianza, el asociacionismo feminista en la red. ${ }^{36}$

\section{Conclusión}

En la actualidad, los discursos feministas motivados por los avances de las tecnologías de comunicación por un lado y las biológicas por

35 WAY, Jenifer, "Digital Art at the Interface of Technology and Feminism" en PAUL, Christian, A Companion to Digital Art, First Edition. Chichester, 2016. John Wiley \&t Sons, Inc., pág. 198.

36 ZAFRA, Remedios. "Redes Y (Ciber)Feminismos. La revolución de la representación que derivó en alianza”, Revista Dígitos, 4, 2018, pág. 22. 
otro, obligan a resituarse como seres humanos dentro de este contexto actual tan particular. Con el antecedente de las teorías transhumanistas y del ciberpunk ejemplificado en las pioneras del ciberfeministmo, observamos que lo ocurrido en el presente, más que una evolución del pensamiento de insurgencia, es un cambio en el campo de batalla. La red ya no es lo que era, no sólo porque se han diluido las promesas de libertad que conllevó en un primer momento, sino porque cada vez la sociedad es más consciente de cómo una gran cantidad de estrategias de control se aplican sobre los usuarios. De igual forma, la ciencia y la tecnología de mejora del ser humano, responde y está influenciada por intereses corporativistas que representan un nuevo orden colonial. Un orden sobre el que se revelan obras como "Future flora" de Tomasello o "Abortion drone", ejemplos cuestionadores de la colonización de los recursos tecnológicos y genopolíticos, así como de la aplicación de valores morales sobre los mismos. De la misma forma, la tecnología de última generación permite reflexionar sobre la interseccionalidad entre género, sexo y raza, un panorama político y cultural presidido aun por esquemas heteropatriarcales coloniales. Tal es el caso de "Bina 48 " de Stephanie Dinkins que promueve todas estas reflexiones a partir del aprendizaje de una inteligencia artifical, mujer afrodescendiente y su relación con el mundo. Ante este nuevo y desolador panorama, los discursos subversivos, en concreto los artísticos, han evolucionado. No es un cambio en esencia, es un replanteamiento de nuevas epistemologías que igualen y faciliten el encuentro entre la biología y la tecnología y que acaben con el esquema dialéctico cartesiano. Modos de hacer que aprovechen la capacidad de conexión de la red estableciendo alianzas como estrategias. "Period Share" y "A piece of pie chart", son obras que promueven ese asociacionismo y visibilizan al colectivo femenino dentro de los procesos culturales, así como aspectos considerados tabú de su naturaleza como la menstruación . Parece que, con mayor o menor éxito, se avanza hacia eso, hacia el entendimiento parangonable de una nueva esencia híbrida que pueda plantear nuevas identidades más allá de los poscuerpos planteados por el ciberfeminismo tradicional, nuevos enfoques sobre el género, y también nuevos ciudadanos empoderados que no solo habitan lo tecnológico, sino que lo utilizan como arma y se materializa entre otros aspectos en excepcionales obras artísticas $^{37}$. Se plantea una nueva bioética, afin al transhumanismo en su dimensión especuladora, un terreno virgen sobre el que erigir una nueva dimensión política. Un pulso contra las corporaciones y el patriarcado corporativista que deriva de la desintegración y el individualismo del esquema neoliberal aparentemente agotado y agonizante, pero más vigente que nunca.

${ }_{37}$ KEMBER, Sarah, Ciberfeminism and artificial life, Routledge, Londres, 2003, pág 9. 